\title{
Mental Health Nurses Experience in Assessing the Early Detection Emergency Psychiatric of Adult in Emergency Department: A Phenomenology Study
}

\author{
Retna Tri Astuti ${ }^{1 *}$, Muhammad Khoirul Amin ${ }^{1}$ \\ ${ }^{1}$ Department of Nursing, Universitas Muhammadiyah Magelang, Magelang, Indonesia \\ *Corresponding author. Email: retnatriastuti@ummgl.ac.id
}

\begin{abstract}
The purpose of this study was to identify the assessment of early detection of emergencies in adult mental patients in Magelang Mental Hospital, Central Java, Indonesia. This qualitative study was conducted from December to May 2019 at Prof. Mental Hospital Dr. Soeroyo Magelang, Central Java, Indonesia. We selected a total of 11 study participants for in-depth interviews. We conducted a content analysis technique by verbatim transcripts of interviews using open code software. This study produced four categories of early detection assessments of emergencies in adult mental patients in the Mental Emergency Unit namely psychological responses, physiological responses, limitations on psychiatric emergency assessments, and HR quality improvement and documentation systems. Some nurses found it difficult to carry out early detection of psychiatric emergencies, given the confusing symptoms and differences in perceptions of assessment and how to assess the instruments already in the hospital. In addition, many documentation systems also became obstacles in the assessment of early detection of emergency adult mental patients at the Mental Hospital. Apart from the system of handling emergencies, especially in terms of the assessment or early detection of standardized emergencies, another problem is the form of an early detection assessment instrument that varies with many items and creates different perceptions. Based on this, an innovative approach is needed to develop an instrument for assessing the early detection of emergency mental disorders that can accommodate the symptoms caused. In addition, the duties of nurses and documentation systems need to be evaluated and oriented.
\end{abstract}

Keywords: nurses, detection emergency psychiatric, emergency department

\section{INTRODUCTION}

Mental health in Indonesia is a challenge for health for the community. A summary of global and WHO regional prevalence of this disorder is shown below. Globally, it is estimated that $4.4 \%$ of the global population suffers from depression, and $3.6 \%$ of anxiety disorders. There is little variation around this global prevalence rate in the WHO Region: for depression, this number varies from $3.6 \%$ in the Western Pacific Region to $5.4 \%$ in the African Region; for anxiety disorders, rates vary from $2.9 \%$ in the Western Pacific Region to $5.8 \%$ in the Americas [1]. While other sources state that the prevalence of mental disorders, especially schizophrenia, is 4.6 / 1000 [2]. While the prevalence of mental disorders in Indonesia according to Riskesdas 2018 reaches 7.0 per mile, the prevalence of depression at the age of more than 15 years reaches 6.1 per Mil and the prevalence of emotional disorders over 15 years old reaches 9.8 per Mil [3] [4].

The state of mental disorders experienced by individuals will be at high risk of emergencies that can injure themselves, others and the environment. Psychiatric emergencies are an acute disorder of a patient's behaviour, thoughts or moods which if left untreated can cause harm, both to individuals or to others in the environment [5]. This psychiatric emergency can occur anywhere and is no exception in the health care unit. Professional health care teams must always be responsive and able to provide prompt and appropriate services for the appearance of worsening symptoms in patients [6]. When emergencies nurses and health workers can carry out a complete assessment of behaviours that reduce risk by transferring patients to the emergency department, and providing or arranging follow-up. The initial assessment should focus on factors that increase the risk of intentional or unintentional harm to the patient. In addition to suicide statements or suicidal ideas, important risk factors for future hazards include evidence of poisoning, expressions of despair, irritable influences, thought disorganization, dishevelled appearance, and psychomotor agitation [7].

Psychiatric emergency assessments are challenging and full of errors. The result of the challenge study in psychiatric assessment is that there is a change in 2ehaviour of patients who can be at risk of errors in assessment and treatment so that it can lead to legal problems so that careful and precise assessment is needed [8]. Whereas the results of other studies state that psychiatric emergency assessments of anxious patients experience difficulties, in cooperability and inability to provide information will complicate the determination of diagnosis and action [9]. Therefore our 
study aims to explore the early assessment of emergency adult mental disorders in the emergency unit of the Mental Hospital in Magelang, Central Java Province, Indonesia.

\section{METHODS}

\subsection{Research Setting}

This research was conducted in Professor Soeroyo Psychiatric Hospital at Magelang City, Central Java Province, Indonesia from December 2018 - May 2019. This research was conducted on emergency department and psychiatric intensive care unit.

\subsection{Study Design}

We conduct qualitative research with a phenomenological approach that emphasizes the subjective experience of participants in a study of a phenomenon [10]. This approach is appropriate for addressing our research objectives: identifying the assessment of early detection of emergencies in adult mental patients at Magelang City, Central Java Province, Indonesia.

\subsection{Researcher's Characteristics and Reflexivity}

RTA and MKA have experience in conducting qualitative research and experience in community involvement. All writers are familiar with the context of the study area and are used to communicating using Javanese. We build relationships with research participants by introducing our position as researchers and carefully making informed consent.

\subsection{Studying Informants and Sampling}

We selected respondents in this case nurses with sample criteria based on work, education, work experience, and placement of work offices namely nurses who work in the emergency room both in the emergency room and psychiatric intensive care unit. We selected a total of 11 study participants for in-depth interviews. Therefore, we can explore the experience of nurses in conducting early detection of emergency adult mental disorders.

\subsection{Data Collection}

Data was collected through in-depth interviews by RTA and MKA. Interviews were conducted in male and female emergency room and psychiatric intensive care unit. In conducting interviews we offer participants to conduct interviews in Javanese or Indonesian. We conducted interviews in accordance with the interview guide to discuss the assessment of early detection of psychiatric emergencies, especially in patients with adult mental disorders. The interview guide contains topics about:

a. Experience in conducting an assessment of the emergency early detection of adult mental disorders,

b. Obstacles in assessing the early detection of emergency adult mental disorders, and

c. Expectations for efforts to assess the early detection of emergency emergencies in adult mental disorders.

\subsection{Data Processing and Analysis}

Interviews conducted by way of recorded and written for word-to-word transcripts. Analysis was carried out on directed content, carried out to evaluate the data obtained [11]. In conducting analysis, we use software that is used to help extract units of meaning, codes and categories from transcripts. RTA and MKA do coding independently. The consensus reached by the results was then discussed further. Examples of the coding process are presented in Table 1 below.

Table 1 Synthesis of data: coding and categories

\begin{tabular}{|c|c|c|}
\hline Categories & Sub categories & Codes \\
\hline \multirow{8}{*}{$\begin{array}{l}\text { Psychological } \\
\text { response }\end{array}$} & \multirow{3}{*}{ Changes in behavior } & Changes in behavior \\
\hline & & Changes can be seen in behavior \\
\hline & & First observation of behavior \\
\hline & \multirow{2}{*}{ Tension } & A change in tension \\
\hline & & Observation of changes in tension \\
\hline & \multirow{3}{*}{ Anxiety } & Symptoms of nervousness \\
\hline & & $\begin{array}{l}\text { The presence of nervous anxiety and the desire to leave } \\
\text { the hospital }\end{array}$ \\
\hline & & The patient is confused and there will be a nervousness \\
\hline \multirow{4}{*}{$\begin{array}{l}\text { Physiological } \\
\text { response }\end{array}$} & \multirow{2}{*}{ Changes in vital signs } & Check vital signs \\
\hline & & Check EWS (pulse, tension, breath, temperature) \\
\hline & \multirow{2}{*}{ Other physical complaints } & Check for wounds, risk of falls, dehydration \\
\hline & & Monitor physical changes from head to toe \\
\hline \multirow{3}{*}{$\begin{array}{l}\text { Limitations on } \\
\text { psychiatric }\end{array}$} & \multirow{3}{*}{ Perception assessment constraints } & Misjudgment of the patient's condition \\
\hline & & Differences in the assessment of the patient's condition \\
\hline & & Confused by the worsening condition of the patient \\
\hline
\end{tabular}




\begin{tabular}{|c|c|c|}
\hline Categories & Sub categories & Codes \\
\hline \multirow[t]{3}{*}{$\begin{array}{l}\text { emergency } \\
\text { assessments }\end{array}$} & $\begin{array}{l}\text { Limited knowledge of the patient's } \\
\text { emergency conditions }\end{array}$ & $\begin{array}{l}\text { Confusion distinguishes the condition of a psychiatric } \\
\text { emergency patient with a general condition }\end{array}$ \\
\hline & \multirow[b]{2}{*}{ Limited assessment skills } & Different ways of evaluating a patient's condition \\
\hline & & $\begin{array}{l}\text { Differences in analyzing the deterioration of the patient's } \\
\text { condition }\end{array}$ \\
\hline \multirow{6}{*}{$\begin{array}{l}\text { HR quality } \\
\text { improvement } \\
\text { system and } \\
\text { documentation }\end{array}$} & \multirow{2}{*}{$\begin{array}{l}\text { Expectations of ease of } \\
\text { documentation }\end{array}$} & The desire for ease in documentation \\
\hline & & Practical documentation system \\
\hline & \multirow{2}{*}{$\begin{array}{l}\text { Hopes of improving the quality of } \\
\text { human resources }\end{array}$} & The desire for training \\
\hline & & Lack of training \\
\hline & \multirow{2}{*}{$\begin{array}{l}\text { Ease of emergency assessment } \\
\text { systems }\end{array}$} & The desire for more practical instrument items \\
\hline & & More practical instrument \\
\hline
\end{tabular}

\subsection{Trustworthiness}

We triangulate the information gathered from nurses to improve the validity of our results. Peer interviews between all authors were conducted to discuss the codes and categories generated from the data.

\subsection{Research Ethics}

We made written individual informed consent from research participants, including their agreement to record interviews. Administrative procedures in the study were followed before we conducted the study. Informal identity during data analysis and reporting is kept confidential. This study received ethical permission from the Ethics Committee, Professor Soeroyo Psychiatric Hospital at Magelang City, Central Java Province, Indonesia.

\section{RESULTS}

There were 11 participants who participated in this study. Most are nurses who serve in the emergency room, and psychiatric intensive care unit, work experience of more than 1 year and have attended 1-time emergency training. The results of the qualitative analysis obtained 4 categories, 11 sub categories and 24 codes. The categories found were psychological responses, physiological responses, limitations on psychiatric emergency assessments, and human resources quality improvement systems and documentation systems. For the sub categories that were formulated there were 11 sub categories which included: changes in behavior, tension, anxiety, changes in vital signs, physical abnormalities, perceived perceptions of constraints, limited knowledge of the patient's emergency conditions, limited assessment skills, expectation of ease of documentation, hope of quality improvement human resources and ease of system assessment of psychiatric emergencies.

\subsection{Psychological Response}

Our study found that early detection by nurses in the assessment of deterioration or emergency adult mental disorders focuses first on the psychological response category. "What is more prominent in patients who experience psychiatric emergencies is their behavior." (Nurse 1, age 42).

\subsection{Physiological Response}

In our physiological response we found results that detection was done focusing on changes in vital signs. This is as stated by the following respondents:

"... and the new program must check the tension, pulse, the EWSS must be controlled." (Nurse 1, age 41 years).

\subsection{Limitations on Psychiatric Emergency Assessments}

The results of this study also found limitations in the early assessment of psychiatric emergencies or mental disorders in adulthood, namely the perception of assessment constraints. This is as expressed by respondents as follows: "Sometimes it often happens wrong ... oh well, if I have a public hospital, how come it actually goes into the soul. This is very fatal. "(Participant 1, age 42 years).

\subsection{HR Quality Improvement System and Documentation}

The results of our study found results related to this category, namely the expectation of documentation and improvement in the quality of human resources. This is according to what was conveyed by respondents, namely: "The training is still lacking in this area. Everyone should have been exposed to psychiatric emergencies, but in part, only a few people, many of whom have not actually been able to update again so that they can be rerefitted. "(Nurse 2, age 32 ).

\section{DISCUSSION}

Our study found the results of an assessment of the early detection of emergency mental disorders in adults: psychological responses, physiological responses, limitations on the designation of psychiatric emergencies and a system for improving the quality of human resources and documentary systems. These findings indicate the 
importance of assessing the early detection of emergency adult mental disorders.

Most of the nurses in this study stated that the assessment of early detection of emergency mental disorders is by assessing behavior, tension, anxiety. Patients who come either in the emergency room or in the intensive care unit experience worsening conditions or experience emergencies often experience changes in their behavior such as around 7\% aggressive behavior, history of suicide, depression and other disorders [12]. Assessment carried out by nurses with observation methods. This is done to prevent possible harm to patients or other people. This is in accordance with research that states that in an emergency situation health personnel conduct rapid assessment and assessment by using a system of observations on behavioral changes such as agitation, tension and impulsivity [13].

Physiological response is the body's response to selfbalance. physiological responses emphasize changes in vital signs. Emergency situations can also result in changes in physiological responses in the body, especially changes in vital signs. When mental patients experience extreme mental stress, the patient's body activates the fight or flight response, where physiological changes will occur, namely the presence of hormone expenditure by the hypothalamus, which will increase blood pressure, pulse, breathing and body temperature [17], [18]. Based on this, monitoring vital signs can play an important role in early detection of deterioration in the patient's condition. Assessment of these vital signs is carried out with a standardized instrument, namely the use of the Early Warning Score System (EWSS) instrument. The Early Warning Score System (EWSS) focused more on changes in vital signs described as a collection of scores of five physiological parameters, namely respiratory frequency, blood pressure, temperature, pulse and neurological status. This Early Warning Score (EWS) has been proven effective from various studies [19]. According to the results of the study, limitations were made regarding the psychiatric emergency assessment in general because emergency nurses and non-psychiatric doctors felt they lacked knowledge and skills in providing psychiatric emergency patient care [20], [21]. This is an important factor and is a special challenge for emergency care providers in the early detection of psychiatric emergencies. The results of other studies suggest that emergency nurses are often asked to assess and manage the care of patients who commit suicide. Another problem is that in providing care to patients there are insufficient resources available, lack of time available to provide care, concerns in carrying out ongoing patient safety, lack of psychiatric inpatient beds resulting in long stays, and feeling helpless on the perceived failure of the mental health system [22], [23]. In addition, other studies also state that the ability of nurses to provide action is influenced by several factors, namely the existence of negative attitudes towards patients with mental illness along with nurses' perceptions of lack of competence and trust in identifying and managing behavioral symptoms. [24] - [26]

The findings in this study are expectations of improving the ability of human resources in this case nurses and documentation of both assessment instruments and service documentation. Education and training play an ongoing role in supporting nurses in their work with emergency patients with mental disorders [27]. Continuous education and training will enhance the ability of nurses to conduct studies and in determining appropriate emergency management measures. Besides the documentation system plays an important activity, good and appropriate documentation is needed in the continuation of the treatment history and patient development. Much documentation causes nurses to be unable to monitor patient progress optimally.

\section{IMPLICATIONS FOR PUBLIC HEALTH PRACTICES}

The findings of this study indicate that nurses who work in emergency units, and psychiatric intensive care unit, must be upgraded and good and appropriate documentation systems are needed. In addition, an innovative approach and appropriate strategies are needed in the emergency assessment of adult mental disorders.

\section{LIMITATIONS AND STRENGTH OF RESEARCH}

This study focuses on exploring the assessment of emergency early detection of adult mental disorders. Does not explain the assessment of management of adult mental disorders.

\section{CONCLUSION}

Our study concludes that the assessment of early detection by bidders has not contributed deeply. Early detection assessments conducted focus on the existence of psychological, physiological responses. The problems caused are limitations on the ability and the need for a proper and accurate documentation system.

\section{ACKNOWLEDGMENT}

We thank all informants for their participation of this study. We also thank Universitas Muhammadiyah Magelang and Professor Soeroyo Psychiatric Hospital at Magelang City, Central Java Province, Indonesia.

\section{REFERENCES}

[1] World Health Organization, "World Health Organization Report - Depression and Other Common Mental Disorders: Global Health Estimates," World Heal. Organ, pp.1-24, 2017.

[2] D. Bhugra, "The Global Prevalence of Schizophrenia," PLoS Med., vol. 2, no. 5, hal. e151, 2005. 
[16] C. S. Hankin, A. Bronstone, dan L. M. Koran, "Agitation in the Inpatient Psychiatric Setting," J. Psychiatr. Pract., vol. 17, no. 3, pp.170-185, 2011.

[17] A. G. Potter, P.A, Perry, Buku Ajar Fundamental Keperawatan: Konsep, Proses Dan Praktek, 4 ed. EGC, 2006.

[5] S. Sudarsanan, S. Chaudhury, A. A. Pawar, S. K. Salujha, dan K. Srivastava, "Psychiatric Emergencies," Med. J. Armed Forces India, vol. 60, no. 1, pp.59-62, 2004.

[6] R. T. Astuti, "Peningkatan Kemampuan Manajemen Kedaruratan Psikiatrik : Panik Bagi Perawat Jiwa Di Rs Jiwa Gracia,” pp.41-43, 2013.

[7] B. M. Newman dan D. Ravindranath, "Managing a Psychiatric Emergency," Psychiatr. Times, vol. 27, no. 7, pp.1-5, 2010.

[8] B. Good, R. Walsh, G. Alexander, dan G. Moore, "Assessment of the Acute Psychiatric Patient in the Emergency Department: Legal Cases and Caveats," West. J. Emerg. Med., vol. 15, no. 3, pp.312-317, 2014.

[9] M. Garriga et al., "Assessment and management of agitation in psychiatry: Expert consensus," World J. Biol. Psychiatry, vol. 17, no. 2, pp.86-128, 2016.

[10] John W. Creswell, "Research Design, Second Edition,” Res. Des. 2nd Ed., pp.3-26, 2003.

[11] H.-F. Hsieh dan S. E. Shannon, "Three approaches to qualitative content analysis," Qual. Health Res., vol. 15, no. 9, pp.1277-88, 2005.

[12] Y. Chaput, L. Beaulieu, M. Paradis, dan E. Labonté, "Aggressive behaviors in the psychiatric emergency service," Open Access Emerg. Med., vol. 3, pp.13-20, 2011.

[13] P. Mavrogiorgou, M. Brüne, dan G. Juckel, "The Management of Psychiatric Emergencies," Dtsch. Aerzteblatt Online, vol. 108, no. 13, pp.222-230, 2011.

[14] K. Stowell, P. Florence, H. Harman, dan R. Glick, "Psychiatric Evaluation of the Agitated Patient: Consensus Statement of the American Association for Emergency Psychiatry Project BETA Psychiatric Evaluation Workgroup,” West. J. Emerg. Med., vol. 13, no. 1, pp.11-16, 2013.

[15] C. G. Huber et al., "Validation of a Clinical Global Impression Scale for Aggression (CGI-A) in a sample of 558 psychiatric patients," Schizophr. Res., vol. 100, no. 1-3, pp.342-348, 2008.
[18] K. B. A. Pasaribu, Prinsip dan Praktik Keperawatan Kesehatan Jiwa Stuart Edisi Indonesia Pertama. 2016.

[19] M. Freeman, "Evidence-based Synthesis Program Early Warning System Scores :," Dep. Veterans Aff., 2014.

[20] D. E. Clarke, L. Hughes, A.-M. Brown, dan L. Motluk, "Psychiatric Emergency Nurses in the Emergency Department: The Success of the Winnipeg, Canada Experience," J. Emerg. Nurs., vol. 31, no. 4, pp.351-356, 2005.

[21] J. T. Gordon, "Emergency department junior medical staff's knowledge, skills and confidence with psychiatric patients: a survey," Psychiatrist, vol. 36, no. 5, pp.186- 188, 2012.

[22] L. Doyle, B. Keogh, dan J. Morrissey, "Caring for patients with suicidal behaviour: an exploratory study," Br. J. Nurs., vol. 16, no. 19, pp.1218-1222, 2014.

[23] R. Egan, K. M. Sarma, dan M. O’Neill, "Factors influencing perceived effectiveness in dealing with selfharming patients in a sample of emergency department staff," J. Emerg. Med., vol. 43, no. 6, pp.1084-1090, 2012.

[24] F. Brinn, "Patients with mental illness: general nurses' attitudes and expectations," Nurs. Stand., vol. 14, no. 27, pp.32-36, 2013.

[25] Reed F; Fitzgerald L, "The mixed attitudes of nurse's to caring for people with mental illness in ...: EBSCOhost," no. February, pp.249-257, 2005.

[26] C. A. Ross dan E. M. Goldner, "Stigma, negative attitudes and discrimination towards mental illness within the nursing profession: A review of the literature," J. Psychiatr. Ment. Health Nurs., vol. 16, no. 6, pp. 558-567, 2009.

[27] L. McCarthy dan H. Gijbels, “An examination of emergency department nurses' attitudes towards deliberate self-harm in an Irish teaching hospital," Int. Emerg. Nurs., vol. 18, no. 1, pp. 29-35, 2010. 